\title{
CONF-950956--9
}

\section{MW UPGRADE \\ TO DIII-D FWCD SYSTEM: \\ SYSTEM COMMISSIONING \\ AND INITIAL OPERATION}

by

W.P. CARY, F.W. BAITY, G.C. BARBER, R.W. CALLIS, J.S. deGRASSIE, S.W. FERGUSON, T.E. HARRIS, R.C. OL'NEILL, and R.I. PINSKER

FEOENTM

PAR 17 TISP?

OSTI

NISTRIDITION OF THIS DOCUMENT IS UNLIMTED 


\section{DISCLAIMER}

This report was prepared as an account of work sponsored by an agency of the United States Government. Neither the United States Government nor any agency thereof, nor any of their employees, makes any warranty, express or implied, or assumes any legal liability or responsibility for the accuracy, completeness, or usefulness of any information, apparatus, product, or process disclosed, or represents that its use would not infringe privately owned rights. Reference herein to any specific commercial product, process, or service by trade name, trademark, manufacturer, or otherwise, does not necessarily constitute or imply its endorsement, recommendation, or favoring by the United States Government or any agency thereof. The views and opinions of authors expressed herein do not necessarily state or reflect those of the United States Government or any agency thereof. 


\section{DISCLAIMER}

Portions of this document may be illegible in electronic image products. Images are produced from the best available original document. 


\title{
4 MW UPGRADE TO DIII-D FWCD SYSTEM: SYSTEM COMMISSIONING AND INITIAL OPERATION
}

by

W.P. CARY, F.W. BAITY,* G.C. BARBER,* R.W. CALLIS, J.S. deGRASSIE, S.W. FERGUSON, ${ }^{\dagger}$

T.E. HARRIS, R.C. OL'NEILL, and R.I. PINSKER

This is a preprint of a paper presented at the 16th IEEE/NPSS Symposium on Fusion Engineering, September 30-October 5, 1995, Champaign, Illinois, and to be printed in the Proceedings.

\author{
Work supported by \\ U.S. Department of Energy Contracts \\ DE-AC03-89ER51114, DE-AC05-840R21400, \\ and $W-7405-E N G-48$
}

*Oak Ridge National Laboratory

${ }^{\dagger}$ Lawrence Livermore National Laboratory

GENERAL ATOMICS PROJECT 3466 OCTOBER 1995 


\title{
4 MW Upgrade to DII-D FWCD System: System Commissioning and Initial Operation*
}

\author{
W.P. Cary, ${ }^{\text {a }}$ F.W. Baity, ${ }^{\mathrm{b}}$ G.C. Barber, ${ }^{\mathrm{b}}$ R.W. Callis, ${ }^{\mathrm{a}}$ J.S. deGrassie, ${ }^{\text {a S.W. Ferguson, }}$, T.E. Harris, ${ }^{\mathrm{a}}$ \\ R.C. O'Neill, ${ }^{a}$ R.I. Pinsker ${ }^{a}$ \\ ${ }^{a}$ General Atomics, P.O. Box 85608, San Diego, California 92186-9784 \\ b Oak Ridge National Laboratory, P.O. Box 2009, Oak Ridge, Tennessee 37831 \\ ${ }^{c_{L}}$ Lawrence Livemore National Laboratory, P.O. Box 808, Livermore California 94551-9900
}

\begin{abstract}
The initial installation of the $4 \mathrm{MW}$ fast wave current drive (FWCD) upgrade started in 1992 with the purchase of two ABB/Thomcast AG rf power amplifiers. These amplifiers cover the frequency range $30 \mathrm{MHz}$ to $120 \mathrm{MHz}$. A maximum output power of over $2 \mathrm{MW}$ between $30 \mathrm{MHz}$ and $80 \mathrm{MHz}$ and $1 \mathrm{MW}$ at $120 \mathrm{MHz}$ were the specification requirements. The system as installed is comprised of the two mentioned if amplifiers, coaxial transmission and matching components, if phase and amplitude monitoring, and a SUN SparcStation 10 control system.
\end{abstract}

Due to various reasons almost every major component in the system required redesign and engineering in order to meet the system requirements. The failures, probable cause and the final redesigns will be discussed as well as some thoughts on how better to specify system requirements for future systems.

\section{INTRODUCTION}

The DII-D $4 \mathrm{MW}$ ICH upgrade can be thought of as being comprised of three major categories: the if sources, the transmission and matching system, and the controlling software and electronics (Fig. 1). The philosophy from the onset of the project was to minimize the risks inherent with development programs and stay with components having a proven track record. The vendor choices were to be judged not only on a competitive cost basis but also on their perceived capabilities and expertise. This meant that we would be looking at mostly "off the shelf" type components. It was felt that this would eliminate the time consuming task of development and have the added advantage of proven reliability; unfortunately this did not prove to be the case. Initially, we assumed that our vendors had the expertise and experience to design a system which would meet our specifications, but in retrospect in some cases the tasks

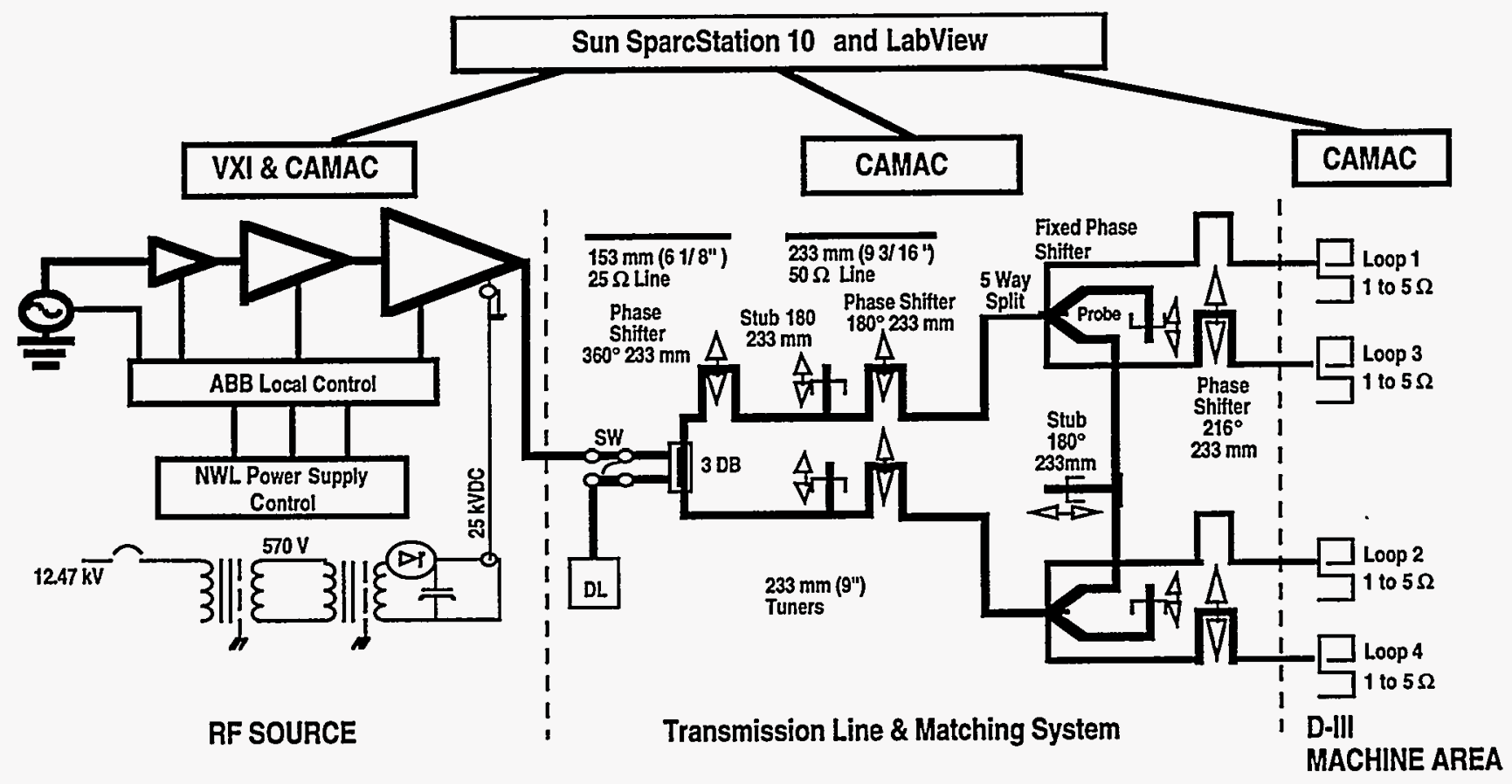

Fig. 1. Simplified diagram of one of the new fast wave current drive systems.

\footnotetext{
*Work supported by the U.S. Department of Energy under Contract Nos. DE-AC03-89ER51114, DE-AC05-84OR21400 and W-7405-ENG-48.
} 
proved beyond the experience base and technical expertise of the vendor staff. The major problem areas and their resolutions will be presented in the following sections.

\section{RF SOURCES}

The sources can be further subdivided into the three general areas of control, rf amplifiers, and High Voltage Power Supplies (HVPS). Owing to schedule constraints it was determined early in the procurement phase that a complete system test could not be performed anywhere except after installation at DIII-D. Because of this, only limited testing of the various subsystems could be completed at the various manufacturing facilities. This was felt to be a low risk plan since there had already been six of the if sources already built [1], so these two could be considered to be production units.

Installation of the two amplifiers, and their associated HVPS went smoothly. It was not until checkout was started that the deficiencies were identified. Many control functions failed to work properly. In some cases there were problems with the traces on the circuit boards. There were also a number of logic and voltage level interfacing problems.

The rf amplifiers have not been immune to failure either. To date there have been three tube failures in the final stage. All three tubes have been analyzed by the factory and found to have similar control grid to cathode shorts. The cause of these failures has not yet been determined; however, these failures have led the tube manufacturer to impose more conservative operating limits which in turn have made it more difficult for the rf amplifiers to meet their design specifications. The most troublesome problem to date has been an oscillation occurring in the final stage at approximately $750 \mathrm{MHz}$ that occurs when the rf absorber is removed from around the tube or when degraded due to overheating. The transmitter specifications call for removal of $r$ absorber material above $80 \mathrm{MHz}$ but due to the parasitic oscillations the rf absorber was required for high power operation. This would not present a problem, except that due to excessive heating of the rf absorber by the fundamental power we have been forced to operate at reduced pulse length. Testing of the material showed that temperatures in excess of $300^{\circ} \mathrm{C}$ would easily be exceeded while not exceeding the original transmitter specifications. Futhermore, these high temperatures have been observed to degrade the absorptivity of the material which eventually caused the material to fail as an absorber (manufacturer's maximum operating temperature is $200^{\circ} \mathrm{C}$ ). A water cooled version of the rf absorber has been furnished by Thomcast but not yet tested as of this writing.

With full power ( $>2 \mathrm{MW})$ and long pulses $(>3 \mathrm{~s})$ we are starting to see signs of tube problems. There is a gradual increase in anode current after removal of rf drive and there is also a negative screen grid current transient seen at the beginning of this anomaly (Fig. 2). This may be due to secondary heating effects. Owing to lack of a tube vac-ion pump it is not known if there is an increase in tube pressure. The tube manufacturer has been made aware of the problem and we are awaiting their response.

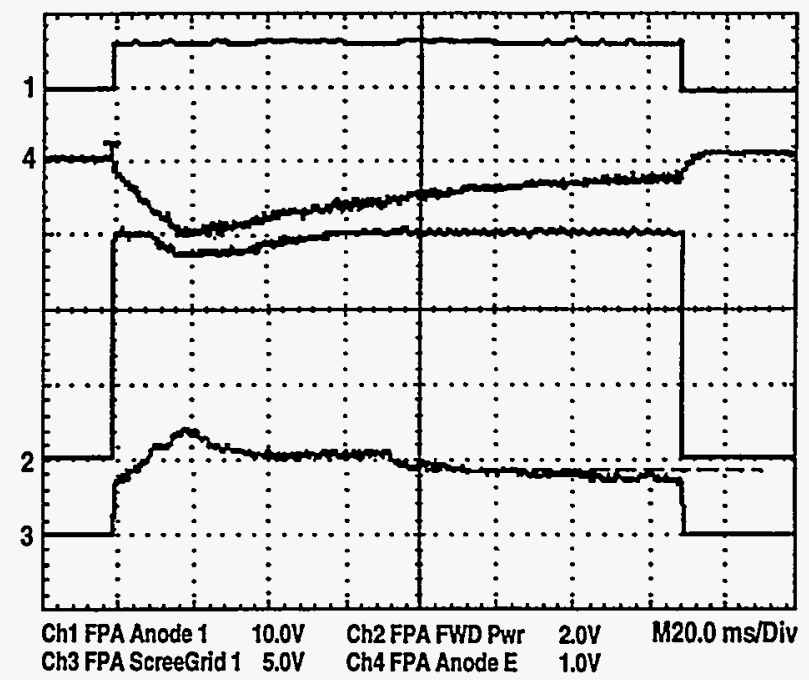

Fig. 2. Anode voltage droop.

The HVPS has also been a source of several problems. Early If testing revealed only minor problems, but as the power levels and pulse lengths were increased several new problems were encountered. The first of the major problems was with the voltage regulation of the anode voltages for the final power amplifier and driver tubes. Several attempts were made by the manufacturer and a continuing effort by us has yielded only marginal improvement. The major problem occurs in the beginning of the pulse where the voltage sags more than $5 \mathrm{kV}$ (specification calls for less than $2.5 \mathrm{kV}$ ) in $25 \mathrm{~ms}$ before responding and another $25 \mathrm{~ms}$ to return to the nominal operating voltage (see Fig. 3). This loss of voltage causes an excess amount of screen grid current in the beginning of the pulse, resulting in a loss of transmitter output power, and potential shutdown on a screen overcurrent fault. This voltage droop can be compensated for by increasing the requested voltage, but at the risk of running into anode dissipation problems when the voltage returns to the requested voltage level.

Inadequate regulation has not been the only problem with the HVPS. During testing at DIII-D the main step-down transformer $(12.47 \mathrm{kV}$ to $570 \mathrm{~V})$ had a failure of the insulation at the winding margin. The repair of this unit required return to the vendor and took over three months to complete. Even the vacuum circuit breakers have been a source of problems. The breakers have failed several times with parts either fracturing or becoming disconnected.

The If source manufacturer has been very responsive to our problems, and have provided engineering support on several occasions. Unfortunately, the problems encountered did impact the timely completion of the upgrade system.

\section{TRANSMISSION AND MATCHING SYSTEM}

After determining the actual components desired (i.e., phase shifters elbow, etc.) the component design responsibility was given to the two selected vendors. One manufacturer was chosen to supply the standard 6 in. and 9 in. transmission line 


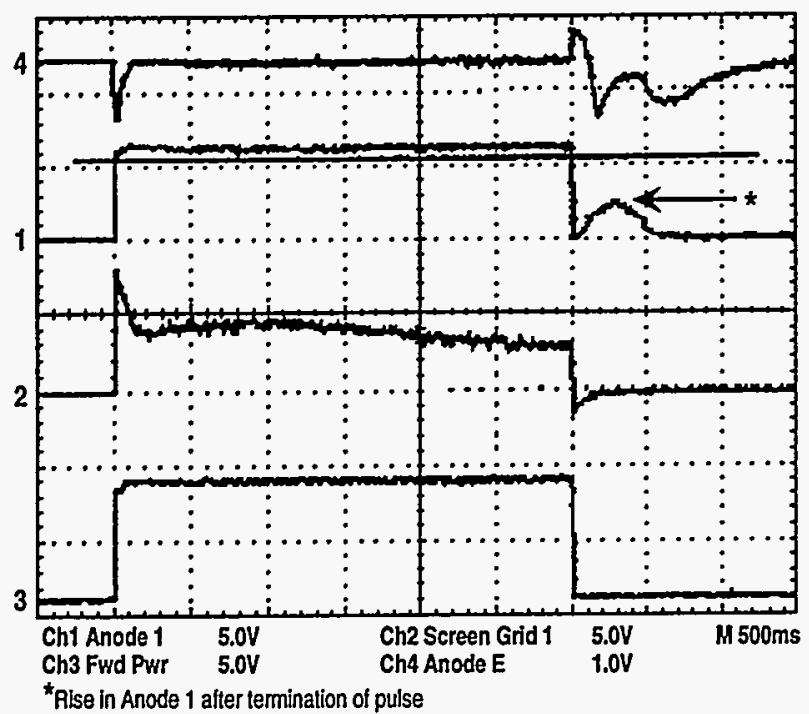

Fig. 3. Secondary emissions.

components while the other was chosen to supply the special components such as the hybrid and the tuning elements.

In order to improve the high voltage capability of the transmission line components, a decision was made to disallow any organic material from being used inside the transmission lines. This was based on our experience with Teflon (the industry standard) in a previous system, because of its degrading after an arc had occurred, and our positive experience with 6 in. coaxial line using ceramic standoffs. The ceramic material selected was unable to support the specified if voltages. A poor design of the triple point interface (insulator/gas/conductor) required considerable time and effort at GA to develop a workable solution [2].

The vendor's choice of insulating materials for the tuning elements proved problematic. An epoxy glass material (G-7), with continuous fibers running along the length of the shaft, was chosen to be the push rod for the center conductor. When the tuning elements were positioned near the minimum length position and this coincided with the rf voltage being near maximum at the rod-to-conductor junction, a failure occurred. Repeated pulses with this condition caused a short to develop between the center and the outer conductor with a path along the insulating rod. The correction for this failure was the replacement of the fiberglass rod with a homogenous plastic rod (Delrin), which caused us much lost time due to the difficulty in effecting a repair to the units. Testing in our rf high potter [2] revealed $<47 \mathrm{kV}$ peak rf voltage for breakdown in $15 \mathrm{lbs}$., SF6 for the G-7 rod and $>72 \mathrm{kV}$ peak for the Delrin rod. Our design goal was to have all $50 \Omega$ components capable of holding off $>70 \mathrm{kV}$ peak if voltage. Several mechanical aspects of the moveable tuning elements have proven troublesome. Several failures of the mechanical drive system in the tuning elements have occurred. The motor to worm gear couplings has been a continuing source of problems.

\section{SOFTWARE AND COMPUTER CONTROL}

Of the three major categories, the software and computer control system seemed to be the least troublesome. A Sun SparcStation 10 was chosen as the computer platform, due to its UNIX environment and supposed ease of integration with the existing DII-D computer systems. Lab View and VXI were chosen as the software-hardware configuration due to the strong industry support of both. The Sun was not as easy to set up and connect to the other computers as was first thought. At the beginning of this program National Instruments had just started to introduce a new version of Lab View for the Sun, so what was first envisioned as a six month effort turned into an 18 month task. The VXI hardware and the vendor support was not up to speed in the beginning compared with our old tried and true CAMAC equipment. This caused some delays in the implementation of the VXI based control. If we were looking at doing this again, CAMAC would probably be the hardware of choice [3].

\section{CONCLUSION}

Several observations can be made after this two year effort. The first and probably the most significant to the fusion community is that there is currently no such thing as an "offthe-shelf" $2 \mathrm{MW}$ rf system. Second, vendor experience and expertise with high power long pulsed rf systems is rather limited. Our experience indicates that the end users must take an active and possibly leading role in the solution of these engineering problems. Lastly, when a new system is specified strong consideration should be given to spending the up front money to have the systems demonstrated and acceptance testing performed at the factory or at the site as part of a fixed price contract.

All things considered, there have been many successes with the introduction of the upgrade. The problems with the various components have been mostly resolved and the transmitters have operated into DIII-D plasmas with a combined rf source output power in excess of $3.6 \mathrm{MW}$. This is $90 \%$ of the rated power and we expect to achieve full power in the near future.

\section{REFERENCES}

[1] W. Schminke, et al., "Upgrade of ICRH generators for ASDEX/W VII, in proc. 12th Symposium on Engineering Problems of Fusion Research, 1987.

[2] S.W. Ferguson, et al., "High voltage performance of $\mathrm{rf}$ transmission line components on the DIII-D fast wave current drive system," this conference.

[3] T.E. Harris, "System control and data acquisition of the two new FWCD rf systems at DIIl-D," this conference. 